NUWC-NPT Technical Report 11,508

1 March 2004

\title{
A Reduced-Order Model of a Fluid-Loaded, Elastomeric-Coated Metallic Plate
}

Andrew J. Hull

Autonomous Systems and Technology Department

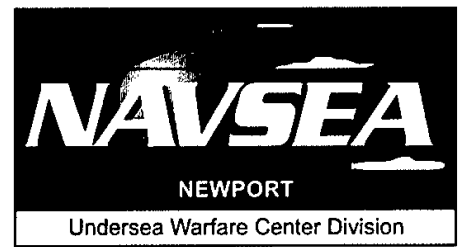

\section{6}

\section{Naval Undersea Warfare Center Division Newport, Rhode Island}

Approved for public release; distribution is unlimited. 


\section{PREFACE}

This report was prepared under Project No. 04PR05704-00, "Modeling the Acoustic Response of a Torpedo Sonar Window," principal investigator Andrew J. Hull (Code 8212). The sponsoring activity is the Office of Naval Research, David Drumheller (Code 333).

The technical reviewer for this report was Benjamin A. Cray (Code 821).

The author wishes to thank Patricia O'Donnell (Code 5431) for her help with the editing of this manuscript.

Reviewed and Approved: 1 March 2004

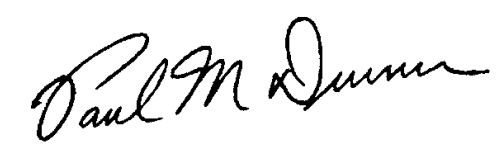

Paul M. Dunn

Head, Autonomous Systems and Technology Department 


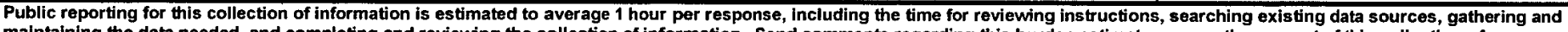
maintaining the data needed, and completing and reviewing the collection of information. Send comments regarding this burden estimate or any other aspect of this collection of information, including suggestions for reducing this burden, to Washington Headquarters Services, Directorate for Information Operations and Reports, 1215 Jefferson Davis Highway, Suite 1204, Arlington, VA 22202-4302, and to the Office of Management and Budget, Paperwork Reduction Project (0704-0188), Washington, DC 20503.

\begin{tabular}{|c|c|c|}
\hline 1. AGENCY USE ONLY (Leave blank) & $\begin{array}{l}\text { 2. REPORT DATE } \\
1 \text { March } 2004\end{array}$ & 3. REPORT TYPE AND DATES COVERED \\
\hline
\end{tabular}

\section{TITLE AND SUBTITLE}

5. FUNDING NUMBERS

A Reduced-Order Model of a Fluid-Loaded, Elastomeric-Coated Metallic Plate

\section{AUTHOR(S)}

Andrew J. Hull

\section{PERFORMING ORGANIZATION NAME(S) AND ADDRESS(ES)}

Naval Undersea Warfare Center Division

1176 Howell Street

Newport, RI 02841-1708

8. PERFORMING ORGANIZATION REPORT NUMBER

TR 11,508

\section{SPONSORING/MONITORING AGENCY NAME(S) AND ADDRESS(ES)}

Office of Naval Research

Ballston Centre Tower One

800 North Quincy Street

Arlington, VA 22217-5660
10. SPONSORING/MONITORING AGENCY REPORT NUMBER

\section{SUPPLEMENTARY NOTES}

\section{2a. DISTRIBUTIONIAVAILABILITY STATEMENT}

Approved for public release; distribution is unlimited. 12b. DISTRIBUTION CODE

\section{ABSTRACT (Maximum 200 words)}

This report derives and analyzes a reduced-order model of a fluid-loaded, elastomeric-coated metallic plate. First, a full-order model of the system is derived using thick plate theory for both the elastomeric coating and the metallic plate. This results in open-form equations of the displacement and stress fields. Next, a reduced-order model is derived by changing the modeling theory of the metallic plate from plate equations to discrete mass equations, which results in a four-by-four system matrix. This new matrix can be symbolically inverted to yield closed-form solutions at every frequency and wavenumber. This closed-formed model is more desirable than the open-form model because the interaction of the physical constants in the stress and displacement fields is explicit. The reduced-order model is graphically compared to the full-order model, indicating that the reduced-order model is an accurate representation of the full-order model.

\begin{tabular}{|c|c|c|c|}
\hline \multirow[t]{2}{*}{$\begin{array}{l}\text { 14. SUBJECT TERMS } \\
\text { Fluid Loading }\end{array}$} & \multirow[t]{2}{*}{ Thick Plate Theory } & \multirow[t]{2}{*}{ Thick Plate Modeling } & $\begin{array}{l}\text { 15. NUMBER OF PAGES } \\
41\end{array}$ \\
\hline & & & 16. PRICE CODE \\
\hline $\begin{array}{l}\text { 17. SECURITY CLASSIFICATION } \\
\text { OF REPORT } \\
\text { Unclassified }\end{array}$ & $\begin{array}{l}\text { 18. SECURITY CLASSIFICATION } \\
\text { OF THIS PAGE } \\
\text { Unclassified }\end{array}$ & $\begin{array}{l}\text { 19. SECURITY CLASSIFICATION } \\
\text { OF ABSTRACT } \\
\text { Unclassified }\end{array}$ & $\begin{array}{l}\text { 20. LIMITATION OF ABSTRACT } \\
\text { SAR }\end{array}$ \\
\hline NSN 7540-01-2 & & & $\begin{array}{l}\text { Standard Form } 298 \text { (Rev. 2-89) } \\
\text { Prescribed by ANSI Std. Z39-18 } \\
\text { 298-102 }\end{array}$ \\
\hline
\end{tabular}


TABLE OF CONTENTS

Section

Page

1 INTRODUCTION

1

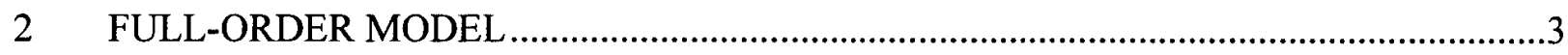

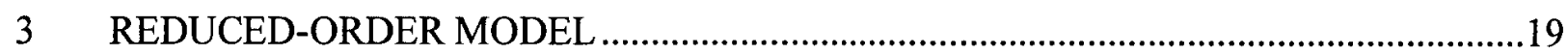

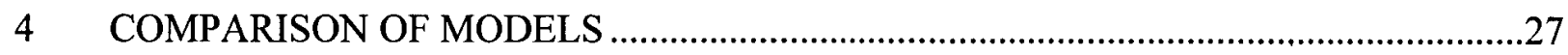

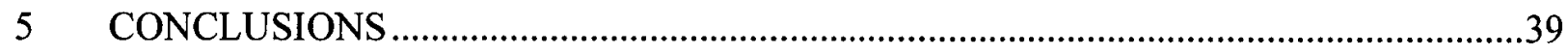

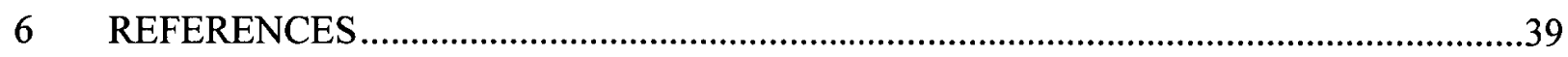

\section{LIST OF ILLUSTRATIONS}

Figure

Page

1 Modeled Geometry and Coordinate System for Full-Order Model ...................................4

2 System Response Versus Incident Angle for $f=10,000 \mathrm{~Hz}$....................................28

3 System Response Versus Incident Angle for $f=20,000 \mathrm{~Hz}$.....................................29

4 System Response Versus Incident Angle for $f=30,000 \mathrm{~Hz}$.......................................30

5 System Response Versus Incident Angle for $f=40,000 \mathrm{~Hz}$......................................3

6 System Response Versus Incident Angle for $f=50,000 \mathrm{~Hz}$......................................32

7 System Response Versus Incident Angle for $f=60,000 \mathrm{~Hz}$.....................................33

8 System Response Versus Incident Angle for $f=70,000 \mathrm{~Hz}$.......................................34

9 System Response Versus Incident Angle for $f=80,000 \mathrm{~Hz}$....................................35

10 System Response Versus Incident Angle for $f=90,000 \mathrm{~Hz}$....................................36

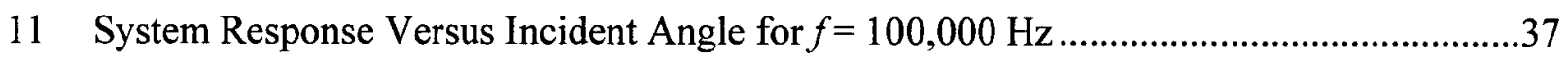




\section{A REDUCED-ORDER MODEL OF A FLUID-LOADED, ELASTOMERIC-COATED METALLIC PLATE}

\section{INTRODUCTION}

Elastomeric-coated metallic plates are used in a wide variety of applications. In marine systems, they are typically used to absorb energy or to transmit acoustic energy from the exterior of an underwater object to a location on the interior of the coating or metallic plate. Sometimes sensors are embedded in the elastomer or the metallic plate to measure the energy field that is insonifying the structure. Energy at different frequencies and wavenumbers will cause a different response in both the coating and the metal. One way to model this response is a fullorder model-i.e., deriving the equation of motion of two thick elastic plates and then coupling them to an acoustic wave equation that models the fluid load. Because the resulting system matrix is eight by eight, this model has a final solution that is expressed in open form, and the system matrix must be numerically inverted at every frequency and wavenumber of interest. It is difficult to understand the physics in such a solution because the interaction of the coefficients in the response is implicit. A second method is to model the metallic plate as a discrete mass, which eliminates one-half of the equations. Once this is done, the system equations have a dimension of four by four, which allows the matrix to be symbolically inverted, yielding a closed-form solution to the problem at every wavenumber and frequency. Closed-form solutions are advantageous because the dynamics associated with the system are explicit. In addition, applying inverse methods to the problem is much easier when a closed-form model is available.

This report develops both a full-order model and a reduced-order model of a fluid-loaded, elastomeric-coated metallic plate and compares the results graphically for system displacements and stresses at various frequencies and wavenumbers. 


\section{FULL-ORDER MODEL}

The transfer functions are derived by modeling the elastomeric coating and the metallic plate as elastic structures, both of which are independently governed by the equation ${ }^{1}$

$$
\mu \nabla^{2} \mathbf{u}+(\lambda+\mu) \nabla \nabla \bullet \mathbf{u}=\rho \frac{\partial^{2} \mathbf{u}}{\partial^{2}},
$$

where $\rho$ is the density, $\lambda$ and $\mu$ are the complex Lamé constants, $t$ is time, $\bullet$ denotes a vector dot product, and $\mathbf{u}$ is the Cartesian coordinate displacement vector expressed as

$$
\mathbf{u}=\left\{\begin{array}{l}
u_{x}(x, y, z, t) \\
u_{y}(x, y, z, t) \\
u_{z}(x, y, z, t)
\end{array}\right\},
$$

with subscript $x$ denoting the direction parallel to the plates, $y$ denoting the direction orthogonal to the $x$-direction, and $z$ denoting the direction normal to the plates. The modeled geometry and the coordinate system of the structure are shown in figure 1 . The symbol $\nabla$ is the gradient vector differential operator written in three-dimensional Cartesian coordinates as ${ }^{2}$

$$
\nabla=\frac{\partial}{\partial x} i_{x}+\frac{\partial}{\partial y} i_{y}+\frac{\partial}{\partial z} i_{z},
$$

with $i_{x}$ denoting the unit vector in the $x$-direction, $i_{y}$ denoting the unit vector in the $y$-direction, and $i_{z}$ denoting the unit vector in the $z$-direction. The symbol $\nabla^{2}$ is the three-dimensional Laplace operator operating on vector $\mathbf{u}$ as

$$
\nabla^{2} \mathbf{u}=\nabla^{2} u_{x} i_{x}+\nabla^{2} u_{y} i_{y}+\nabla^{2} u_{z} i_{z}
$$

with $\nabla^{2}$ operating on scalar $u$ as

$$
\nabla^{2} u_{x, y, z}=\nabla \bullet \nabla u_{x, y, z}=\frac{\partial^{2} u_{x, y, z}}{\partial x^{2}}+\frac{\partial^{2} u_{x, y, z}}{\partial y^{2}}+\frac{\partial^{2} u_{x, y, z}}{\partial z^{2}}
$$


The term $\nabla \bullet \mathbf{u}$ is the divergence, which is equal to

$$
\nabla \cdot \mathbf{u}=\frac{\partial u_{x}}{\partial x}+\frac{\partial u_{y}}{\partial y}+\frac{\partial u_{z}}{\partial z}
$$

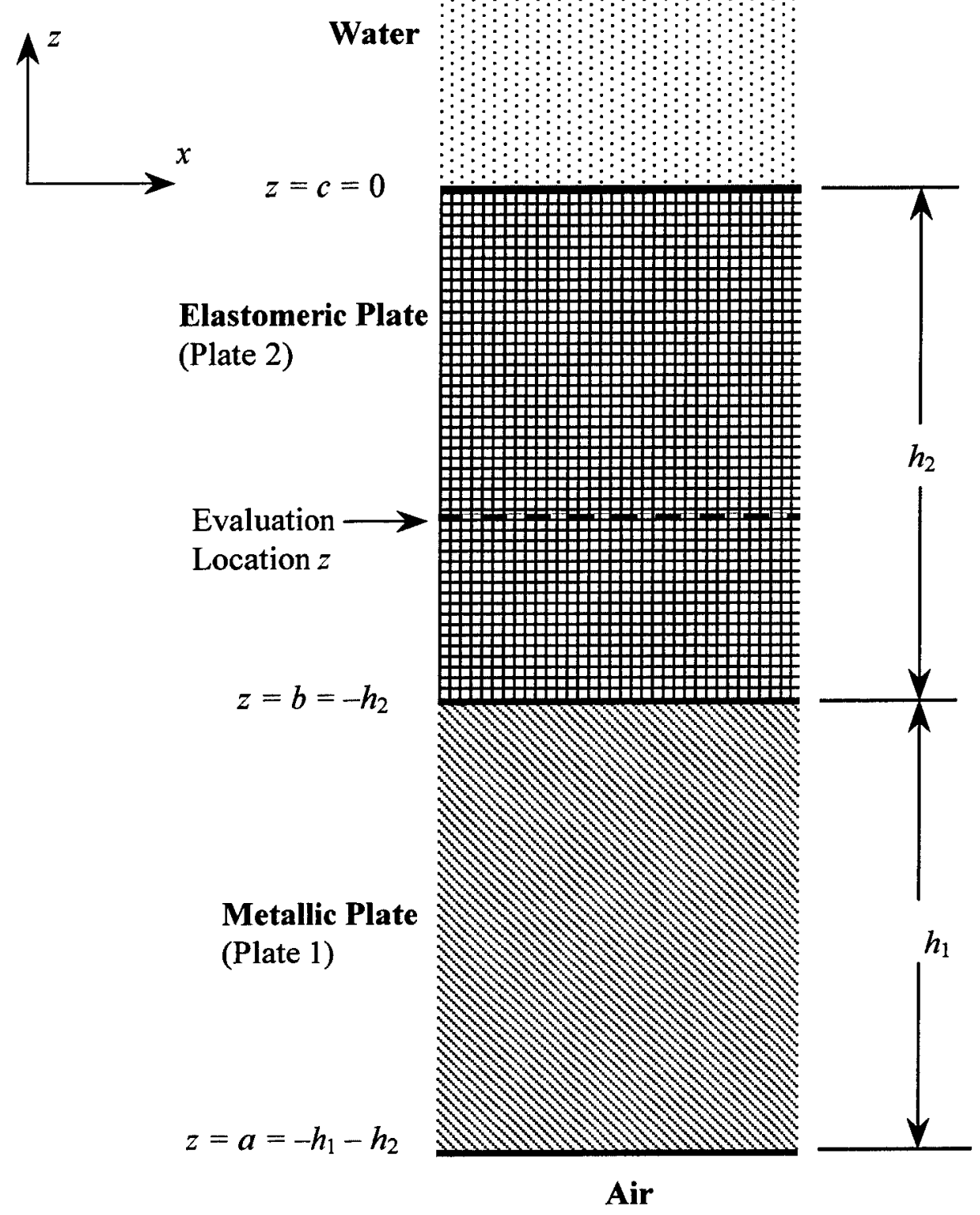

Figure 1. Modeled Geometry and Coordinate System for Full-Order Model 
The applied loading effect of the pressure in the fluid acting on the surface of the top elastomeric plate is modeled as an acoustic load. Note that $\rho, \lambda$, and $\mu$ are the properties of each specific layer.

The displacement vector $\mathbf{u}$ is written as

$$
\mathbf{u}=\nabla \phi+\nabla \times \vec{\psi},
$$

where $\phi$ is a dilatational scalar potential, $\times$ denotes a vector cross product, and $\vec{\psi}$ is an equivoluminal vector potential expressed as

$$
\vec{\psi}=\left\{\begin{array}{l}
\psi_{x}(x, y, z, t) \\
\psi_{y}(x, y, z, t) \\
\psi_{z}(x, y, z, t)
\end{array}\right\} .
$$

The problem is now simplified as a two-dimensional response $(y \equiv 0$ and $\partial(\cdot) / \partial y \equiv 0)$, since it is known that an acoustic plane wave excites the plate. Expanding equation (7) and breaking the displacement vector into its individual nonzero terms yields

$$
u_{x}(x, z, t)=\frac{\partial \phi(x, z, t)}{\partial x}-\frac{\partial \psi_{y}(x, z, t)}{\partial z}
$$

and

$$
u_{z}(x, z, t)=\frac{\partial \phi(x, z, t)}{\partial z}+\frac{\partial \psi_{y}(x, z, t)}{\partial x}
$$

Equations (9) and (10) are next inserted into equation (1), which results in

$$
c_{d}^{2} \nabla^{2} \phi(x, z, t)=\frac{\partial^{2} \phi(x, z, t)}{\partial t^{2}}
$$

and

$$
c_{s}^{2} \nabla^{2} \psi_{y}(x, z, t)=\frac{\partial^{2} \psi_{y}(x, z, t)}{\partial t^{2}}
$$


on both material layers. Equation (11) is the dilatational component and equation (12) is the shear component of the displacement field. ${ }^{3}$ Correspondingly, the constants $c_{d}$ and $c_{s}$ are the complex dilatational and shear wave speeds, respectively, and are determined by

$$
c_{d}=\sqrt{\frac{\lambda+2 \mu}{\rho}}
$$

and

$$
c_{s}=\sqrt{\frac{\mu}{\rho}} .
$$

The relationships of the Lamé constants to the compressional and shear moduli are shown as

$$
\lambda=\frac{E v}{(1+v)(1-2 v)}
$$

and

$$
\mu=G=\frac{E}{2(1+v)},
$$

where $E$ is the complex compressional modulus $\left(\mathrm{N} / \mathrm{m}^{2}\right), G$ is the complex shear modulus $\left(\mathrm{N} / \mathrm{m}^{2}\right)$, and $v$ is the Poisson's ratio of the material (dimensionless).

The conditions of infinite length, two-dimensional response $(y=0)$, and steady-state response are now imposed, allowing the scalar and vector potential to be written as

$$
\phi(x, z, t)=\Phi(z) \exp \left(\mathrm{i} k_{x} x\right) \exp (\mathrm{i} \omega t)
$$

and

$$
\psi_{y}(x, z, t)=\Psi(z) \exp \left(\mathrm{i} k_{x} x\right) \exp (\mathrm{i} \omega t)
$$

where $k_{x}$ is the wavenumber of excitation with respect to the $x$-direction $(\mathrm{rad} / \mathrm{m}), \omega$ is the frequency of excitation ( $\mathrm{rad} / \mathrm{s})$, and $i$ is the square root of -1 . Note that equations (17) and (18) 
are valid on both layers. For acoustic excitation, the wavenumber is related to the incident angle by $k_{x}=\left(\omega / c_{f}\right) \sin (\theta)$, where $\theta$ is the incident angle (rad) with a value of 0 corresponding to broadside excitation.

Inserting equation (17) into equation (11) yields

$$
\frac{d^{2} \Phi(z)}{d z^{2}}+\alpha^{2} \Phi(z)=0,
$$

where

$$
\alpha=\sqrt{k_{d}^{2}-k_{x}^{2}}
$$

and

$$
k_{d}=\frac{\omega}{c_{d}} .
$$

Inserting equation (18) into equation (12) yields

$$
\frac{d^{2} \Psi(z)}{d z^{2}}+\beta^{2} \Psi(z)=0,
$$

where

$$
\beta=\sqrt{k_{s}^{2}-k_{x}^{2}}
$$

and

$$
k_{s}=\frac{\omega}{c_{s}}
$$

The solution to equation (19) is

$$
\Phi(z)=A\left(k_{x}, \omega\right) \exp (\mathrm{i} \alpha z)+B\left(k_{x}, \omega\right) \exp (-\mathrm{i} \alpha z),
$$


and the solution to equation (22) is

$$
\Psi(z)=C\left(k_{x}, \omega\right) \exp (\mathrm{i} \beta z)+D\left(k_{x}, \omega\right) \exp (-\mathrm{i} \beta z)
$$

where $A, B, C$, and $D$ are constants that are determined below. The displacements can now be written as functions of the unknown constants:

$$
\begin{aligned}
u_{z}(x, z, t) & =\left\{\mathrm{i} \alpha\left[A\left(k_{x}, \omega\right) \exp (\mathrm{i} \alpha z)-B\left(k_{x}, \omega\right) \exp (-\mathrm{i} \alpha z)\right]\right. \\
& \left.+\mathrm{i} k_{x}\left[C\left(k_{x}, \omega\right) \exp (\mathrm{i} \beta z)+D\left(k_{x}, \omega\right) \exp (-\mathrm{i} \beta z)\right]\right\} \exp \left(\mathrm{i} k_{x} x\right) \exp (\mathrm{i} \omega t)
\end{aligned}
$$

and

$$
\begin{aligned}
u_{x}(x, z, t)= & \left\{\mathrm{i} k_{x}\left[A\left(k_{x}, \omega\right) \exp (\mathrm{i} \alpha z)+B\left(k_{x}, \omega\right) \exp (-\mathrm{i} \alpha z)\right]\right. \\
& \left.-\mathrm{i} \beta\left[C\left(k_{x}, \omega\right) \exp (\mathrm{i} \beta z)-D\left(k_{x}, \omega\right) \exp (-\mathrm{i} \beta z)\right]\right\} \exp \left(\mathrm{i} k_{x} x\right) \exp (\mathrm{i} \omega t)
\end{aligned}
$$

The solutions of the constants are determined by formulating the problem with the presence of an acoustic load.

The acoustic pressure in the fluid is governed by the wave equation and is written in Cartesian coordinates as ${ }^{4}$

$$
\frac{\partial^{2} p_{a}(x, z, t)}{\partial z^{2}}+\frac{\partial^{2} p_{a}(x, z, t)}{\partial x^{2}}-\frac{1}{c_{f}^{2}} \frac{\partial^{2} p_{a}(x, z, t)}{\partial t^{2}}=0
$$

where $p_{a}(x, z, t)$ is the pressure $\left(\mathrm{N} / \mathrm{m}^{2}\right), z$ is the spatial location (m) normal to the plate, and $c_{f}$ is the compressional wavespeed of the fluid $(\mathrm{m} / \mathrm{s})$. The acoustic pressure is modeled as a function at definite wavenumber and frequency as

$$
p_{a}(x, z, t)=P_{a}\left(z, k_{x}, \omega\right) \exp \left(\mathrm{i} k_{x} x\right) \exp (\mathrm{i} \omega t)
$$

Inserting equation (30) into equation (29) and solving the resulting ordinary differential equation yields

$$
P_{a}\left(z, k_{x}, \omega\right)=G\left(k_{x}, \omega\right) \exp (\mathrm{i} \gamma z)+P_{I}(\omega) \exp (-\mathrm{i} \gamma z),
$$


where the first term on the right-hand side represents the reradiated pressure field and the second term represents the applied incident pressure field (the forcing function) acting on the structure. In equation (31),

$$
\gamma=\sqrt{\left(\frac{\omega}{c_{f}}\right)^{2}-k_{x}^{2}}
$$

where $\gamma$ is purely real or imaginary, depending on the sign of the argument. When the sign of the argument is positive, the analysis is in the acoustic cone, and when the sign of the argument is negative, the analysis is in the nonacoustic region. For acoustic sonar response, the analysis is typically studied in the acoustic cone.

The transfer functions are now derived by coupling the pressure in the fluid to the displacement in the elastomer. The interface between the fluid and the solid surface at $z=c$ satisfies the linear momentum equation, which is ${ }^{5}$

$$
\rho_{f} \frac{\partial^{2} u_{z}(x, c, t)}{\partial t^{2}}=-\frac{\partial p_{a}(x, c, t)}{\partial z}
$$

where $\rho_{f}$ is the density of the fluid $\left(\mathrm{kg} / \mathrm{m}^{3}\right)$. The normal and tangential stresses in the system at the boundary $z=c$ are

$$
\tau_{z z}(x, c, t)=\left(\lambda_{2}+2 \mu_{2}\right) \frac{\partial u_{z}(x, c, t)}{\partial z}+\lambda_{2} \frac{\partial u_{x}(x, c, t)}{\partial x}=-p_{a}(x, c, t)
$$

and

$$
\tau_{z x}(x, c, t)=\mu_{2}\left[\frac{\partial u_{x}(x, c, t)}{\partial z}+\frac{\partial u_{z}(x, c, t)}{\partial x}\right]=0
$$

where the subscript 2 denotes plate 2, which is the elastomer. The interface between the plates requires four equations. The first two equations, which are displacement constraints, are

$$
\left.u_{z}(x, b, t)\right|_{\text {plate 2 }}=\left.u_{z}(x, b, t)\right|_{\text {plate } 1}
$$


and

$$
\left.u_{x}(x, b, t)\right|_{\text {plate } 2}=\left.u_{x}(x, b, t)\right|_{\text {plate } 1},
$$

where plate 1 is the metallic piece. The second two equations are stress constraints:

$$
\left.\tau_{z z}(x, b, t)\right|_{\text {plate } 2}=\left.\tau_{z z}(x, b, t)\right|_{\text {plate } 1}
$$

and

$$
\left.\tau_{z x}(x, b, t)\right|_{\text {plate } 2}=\left.\tau_{z x}(x, b, t)\right|_{\text {plate } 1} .
$$

Finally, the normal and tangential stresses in the system at the boundary $z=a$ are

$$
\tau_{z z}(x, a, t)=\left(\lambda_{1}+2 \mu_{1}\right) \frac{\partial u_{z}(x, a, t)}{\partial z}+\lambda_{1} \frac{\partial u_{x}(x, a, t)}{\partial x}=0
$$

and

$$
\tau_{z x}(x, a, t)=\mu_{1}\left[\frac{\partial u_{x}(x, a, t)}{\partial z}+\frac{\partial u_{z}(x, a, t)}{\partial x}\right]=0
$$

Combining equations (27) through (41) yields the eight-by-eight linear system of equations

$$
\mathbf{A} \mathbf{x}=\mathbf{b}
$$

where, using $c=0$, the entries of equation (42) are

$$
\begin{aligned}
& A_{1,1}=-\alpha_{2}^{2} \lambda_{2}-2 \alpha_{2}^{2} \mu_{2}-\lambda_{2} k_{x}^{2}+\frac{\rho_{f} \omega^{2} \alpha_{2}}{\gamma}, \\
& A_{1,2}=-\alpha_{2}^{2} \lambda_{2}-2 \alpha_{2}^{2} \mu_{2}-\lambda_{2} k_{x}^{2}-\frac{\rho_{f} \omega^{2} \alpha_{2}}{\gamma}, \\
& A_{1,3}=-2 k_{x} \beta_{2} \mu_{2}+\frac{\rho_{f} \omega^{2} k_{x}}{\gamma},
\end{aligned}
$$




$$
\begin{aligned}
& A_{1,4}=2 k_{x} \beta_{2} \mu_{2}+\frac{\rho_{f} \omega^{2} k_{x}}{\gamma}, \\
& A_{1,5}=0 \text {, } \\
& A_{1,6}=0 \text {, } \\
& A_{1,7}=0 \text {, } \\
& A_{1,8}=0 \text {, } \\
& A_{2,1}=-2 \mu_{2} k_{x} \alpha_{2} \text {, } \\
& A_{2,2}=2 \mu_{2} k_{x} \alpha_{2} \text {, } \\
& A_{2,3}=\mu_{2} \beta_{2}^{2}-\mu_{2} k_{x}^{2}, \\
& A_{2,4}=\mu_{2} \beta_{2}^{2}-\mu_{2} k_{x}^{2}, \\
& A_{2,5}=0 \text {, } \\
& A_{2,6}=0 \text {, } \\
& A_{2,7}=0 \text {, } \\
& A_{2,8}=0 \text {, } \\
& A_{3,1}=\left(\mathrm{i} \alpha_{2}\right) \exp \left(\mathrm{i} \alpha_{2} b\right), \\
& A_{3,2}=\left(-\mathrm{i} \alpha_{2}\right) \exp \left(-\mathrm{i} \alpha_{2} b\right), \\
& A_{3,3}=\left(\mathrm{i} k_{x}\right) \exp \left(\mathrm{i} \beta_{2} b\right),
\end{aligned}
$$




$$
\begin{aligned}
& A_{3,4}=\left(\mathrm{i} k_{x}\right) \exp \left(-\mathrm{i} \beta_{2} b\right), \\
& A_{3,5}=\left(-\mathrm{i} \alpha_{1}\right) \exp \left(\mathrm{i} \alpha_{1} b\right), \\
& A_{3,6}=\left(\mathrm{i} \alpha_{1}\right) \exp \left(-\mathrm{i} \alpha_{1} b\right), \\
& A_{3,7}=\left(-\mathrm{i} k_{x}\right) \exp \left(\mathrm{i} \beta_{1} b\right), \\
& A_{3,8}=\left(-\mathrm{i} k_{x}\right) \exp \left(-\mathrm{i} \beta_{1} b\right), \\
& A_{4,1}=\left(\mathrm{i} k_{x}\right) \exp \left(\mathrm{i} \alpha_{2} b\right), \\
& A_{4,2}=\left(\mathrm{i} k_{x}\right) \exp \left(-\mathrm{i} \alpha_{2} b\right), \\
& A_{4,3}=\left(-\mathrm{i} \beta_{2}\right) \exp \left(\mathrm{i} \beta_{2} b\right), \\
& A_{4,4}=\left(\mathrm{i} \beta_{2}\right) \exp \left(-\mathrm{i} \beta_{2} b\right), \\
& A_{4,5}=\left(-\mathrm{i} k_{x}\right) \exp \left(\mathrm{i} \alpha_{1} b\right), \\
& A_{4,6}=\left(-\mathrm{i} k_{x}\right) \exp \left(-\mathrm{i} \alpha_{1} b\right), \\
& A_{4,7}=\left(\mathrm{i} \beta_{1}\right) \exp \left(\mathrm{i} \beta_{1} b\right), \\
& A_{4,8}=\left(-\mathrm{i} \beta_{1}\right) \exp \left(-\mathrm{i} \beta_{1} b\right), \\
& A_{5,1}=\left(-\alpha_{2}^{2} \lambda_{2}-2 \alpha_{2}^{2} \mu_{2}-\lambda_{2} k_{x}^{2}\right) \exp \left(\mathrm{i} \alpha_{2} b\right), \\
& A_{5,2}=\left(-\alpha_{2}^{2} \lambda_{2}-2 \alpha_{2}^{2} \mu_{2}-\lambda_{2} k_{x}^{2}\right) \exp \left(-\mathrm{i} \alpha_{2} b\right), \\
& A_{5,3}=\left(-2 k_{x} \beta_{2} \mu_{2}\right) \exp \left(\mathrm{i} \beta_{2} b\right), \\
& A_{5,4}=\left(2 k_{x} \beta_{2} \mu_{2}\right) \exp \left(-\mathrm{i} \beta_{2} b\right) \text {, }
\end{aligned}
$$




$$
\begin{aligned}
& A_{5,5}=\left(\alpha_{1}^{2} \lambda_{1}+2 \alpha_{1}^{2} \mu_{1}+\lambda_{1} k_{x}^{2}\right) \exp \left(\mathrm{i} \alpha_{1} b\right) \\
& A_{5,6}=\left(\alpha_{1}^{2} \lambda_{1}+2 \alpha_{1}^{2} \mu_{1}+\lambda_{1} k_{x}^{2}\right) \exp \left(-\mathrm{i} \alpha_{1} b\right), \\
& A_{5,7}=\left(2 k_{x} \beta_{1} \mu_{1}\right) \exp \left(\mathrm{i} \beta_{1} b\right) \\
& A_{5,8}=\left(-2 k_{x} \beta_{1} \mu_{1}\right) \exp \left(-\mathrm{i} \beta_{1} b\right), \\
& A_{6,1}=\left(-2 \mu_{2} k_{x} \alpha_{2}\right) \exp \left(\mathrm{i} \alpha_{2} b\right) \\
& A_{6,2}=\left(2 \mu_{2} k_{x} \alpha_{2}\right) \exp \left(-\mathrm{i} \alpha_{2} b\right), \\
& A_{6,3}=\left(\mu_{2} \beta_{2}^{2}-\mu_{2} k_{x}^{2}\right) \exp \left(\mathrm{i} \beta_{2} b\right), \\
& A_{6,4}=\left(\mu_{2} \beta_{2}^{2}-\mu_{2} k_{x}^{2}\right) \exp \left(-\mathrm{i} \beta_{2} b\right), \\
& A_{6,5}=\left(2 \mu_{1} k_{x} \alpha_{1}\right) \exp \left(\mathrm{i} \alpha_{1} b\right) \\
& A_{6,6}=\left(-2 \mu_{1} k_{x} \alpha_{1}\right) \exp \left(-\mathrm{i} \alpha_{1} b\right), \\
& A_{6,7}=\left(-\mu_{1} \beta_{1}^{2}+\mu_{1} k_{x}^{2}\right) \exp \left(\mathrm{i} \beta_{1} b\right), \\
& A_{6,8}=\left(-\mu_{1} \beta_{1}^{2}+\mu_{1} k_{x}^{2}\right) \exp \left(-\mathrm{i} \beta_{1} b\right), \\
& A_{7,1}=0 \text {, } \\
& A_{7,2}=0 \text {, } \\
& A_{7,3}=0 \text {, } \\
& A_{7,4}=0 \text {, }
\end{aligned}
$$




$$
\begin{aligned}
& A_{7,5}=\left(-\alpha_{1}^{2} \lambda_{1}-2 \alpha_{1}^{2} \mu_{1}-\lambda_{1} k_{x}^{2}\right) \exp \left(\mathrm{i} \alpha_{1} a\right), \\
& A_{7,6}=\left(-\alpha_{1}^{2} \lambda_{1}-2 \alpha_{1}^{2} \mu_{1}-\lambda_{1} k_{x}^{2}\right) \exp \left(-\mathrm{i} \alpha_{1} a\right) \text {, } \\
& A_{7,7}=\left(-2 k_{x} \beta_{1} \mu_{1}\right) \exp \left(\mathrm{i} \beta_{1} a\right), \\
& A_{7,8}=\left(2 k_{x} \beta_{1} \mu_{1}\right) \exp \left(-\mathrm{i} \beta_{1} a\right), \\
& A_{8,1}=0 \text {, } \\
& A_{8,2}=0 \text {, } \\
& A_{8,3}=0 \text {, } \\
& A_{8,4}=0 \text {, } \\
& A_{8,5}=\left(-2 \mu_{1} k_{x} \alpha_{1}\right) \exp \left(\mathrm{i} \alpha_{1} a\right), \\
& A_{8,6}=\left(2 \mu_{1} k_{x} \alpha_{1}\right) \exp \left(-\mathrm{i} \alpha_{1} a\right), \\
& A_{8,7}=\left(\mu_{1} \beta_{1}^{2}-\mu_{1} k_{x}^{2}\right) \exp \left(\mathrm{i} \beta_{1} a\right), \\
& A_{8,8}=\left(\mu_{1} \beta_{1}^{2}-\mu_{1} k_{x}^{2}\right) \exp \left(-\mathrm{i} \beta_{1} a\right), \\
& x_{1,1}=A_{2}\left(k_{x}, \omega\right) \text {, } \\
& x_{2,1}=B_{2}\left(k_{x}, \omega\right) \text {, } \\
& x_{3,1}=C_{2}\left(k_{x}, \omega\right) \text {, } \\
& x_{4,1}=D_{2}\left(k_{x}, \omega\right) \text {, } \\
& x_{5,1}=A_{1}\left(k_{x}, \omega\right) \text {, }
\end{aligned}
$$

14 


$$
\begin{aligned}
& x_{6,1}=B_{1}\left(k_{x}, \omega\right), \\
& x_{7,1}=C_{1}\left(k_{x}, \omega\right), \\
& x_{8,1}=D_{1}\left(k_{x}, \omega\right), \\
& b_{1,1}=-2 P_{I}(\omega), \\
& b_{2,1}=0, \\
& b_{3,1}=0 \\
& b_{4,1}=0 \\
& b_{5,1}=0 \\
& b_{6,1}=0 \\
& b_{7,1}=0
\end{aligned}
$$

and

$$
b_{8,1}=0 \text {. }
$$

Using equations (43) through (122), the solution to the constants $A_{1}, B_{1}, C_{1}, D_{1}, A_{2}, B_{2}, C_{2}$, and $D_{2}$ can be found by

$$
\mathbf{x}=\mathbf{A}^{-1} \mathbf{b} \text {. }
$$

The transfer function between the normal displacement at location $z$, when $z \leq b$, and the incident pressure (acoustic load) can be written as 


$$
\begin{aligned}
T\left(z, k_{x}, \omega\right) & =\frac{U_{z}\left(z, k_{x}, \omega\right)}{P_{I}(\omega)} \\
& =A_{1}\left(k_{x}, \omega\right) \mathrm{i} \alpha_{1} \exp \left(\mathrm{i} \alpha_{1} z\right)-B_{1}\left(k_{x}, \omega\right) \mathrm{i} \alpha_{1} \exp \left(-\mathrm{i} \alpha_{1} z\right) \\
& +C_{1}\left(k_{x}, \omega\right) \mathrm{i} k_{x} \exp \left(\mathrm{i} \beta_{1} z\right)+D_{1}\left(k_{x}, \omega\right) \mathrm{i} k_{x} \exp \left(-\mathrm{i} \beta_{1} z\right)
\end{aligned}
$$

or, when $z \geq b$, as

$$
\begin{aligned}
T\left(z, k_{x}, \omega\right) & =\frac{U_{z}\left(z, k_{x}, \omega\right)}{P_{I}(\omega)} \\
& =A_{2}\left(k_{x}, \omega\right) \mathrm{i} \alpha_{2} \exp \left(\mathrm{i} \alpha_{2} z\right)-B_{2}\left(k_{x}, \omega\right) \mathrm{i} \alpha_{2} \exp \left(-\mathrm{i} \alpha_{2} z\right) \\
& +C_{2}\left(k_{x}, \omega\right) \mathrm{i} k_{x} \exp \left(\mathrm{i} \beta_{2} z\right)+D_{2}\left(k_{x}, \omega\right) \mathrm{i} k_{x} \exp \left(-\mathrm{i} \beta_{2} z\right)
\end{aligned}
$$

The transfer function between the tangential displacement at location $z$, when $z \leq b$, and the incident pressure can be written as

$$
\begin{aligned}
T\left(z, k_{x}, \omega\right) & =\frac{U_{x}\left(z, k_{x}, \omega\right)}{P_{I}(\omega)} \\
& =A_{1}\left(k_{x}, \omega\right) \mathrm{i} k_{x} \exp \left(\mathrm{i} \alpha_{1} z\right)+B_{1}\left(k_{x}, \omega\right) \mathrm{i} k_{x} \exp \left(-\mathrm{i} \alpha_{1} z\right) \\
& +-C_{1}\left(k_{x}, \omega\right) \mathrm{i} \beta_{1} \exp \left(\mathrm{i} \beta_{1} z\right)+D_{1}\left(k_{x}, \omega\right) \mathrm{i} \beta_{1} \exp \left(-\mathrm{i} \beta_{1} z\right)
\end{aligned}
$$

or, when $z \geq b$, as

$$
\begin{aligned}
T\left(z, k_{x}, \omega\right) & =\frac{U_{x}\left(z, k_{x}, \omega\right)}{P_{I}\left(k_{x}, \omega\right)} \\
& =A_{2}\left(k_{x}, \omega\right) \mathrm{i} k_{x} \exp \left(\mathrm{i} \alpha_{2} z\right)+B_{2}\left(k_{x}, \omega\right) \mathrm{i} k_{x} \exp \left(-\mathrm{i} \alpha_{2} z\right) \\
& +-C_{2}\left(k_{x}, \omega\right) \mathrm{i} \beta_{2} \exp \left(\mathrm{i} \beta_{2} z\right)+D_{2}\left(k_{x}, \omega\right) \mathrm{i} \beta_{2} \exp \left(-\mathrm{i} \beta_{2} z\right) .
\end{aligned}
$$


The transfer function between the normal stress at location $z$, when $z \leq b$, and the incident pressure can be written as

$$
\begin{aligned}
T\left(z, k_{x}, \omega\right) & =\frac{S_{z z}\left(z, k_{x}, \omega\right)}{P_{I}(\omega)} \\
& =A_{1}\left(k_{x}, \omega\right)\left(-\alpha_{1}^{2} \lambda_{1}-2 \alpha_{1}^{2} \mu_{1}-\lambda_{1} k_{x}^{2}\right) \exp \left(\mathrm{i} \alpha_{1} z\right) \\
& +B_{1}\left(k_{x}, \omega\right)\left(-\alpha_{1}^{2} \lambda_{1}-2 \alpha_{1}^{2} \mu_{1}-\lambda_{1} k_{x}^{2}\right) \exp \left(-\mathrm{i} \alpha_{1} z\right) \\
& +C_{1}\left(k_{x}, \omega\right)\left(-2 k_{x} \beta_{1} \mu_{1}\right) \exp \left(\mathrm{i} \beta_{1} z\right)+D_{1}\left(k_{x}, \omega\right)\left(2 k_{x} \beta_{1} \mu_{1}\right) \exp \left(-i \beta_{1} z\right)
\end{aligned}
$$

or, when $z \geq b$, as

$$
\begin{aligned}
T\left(z, k_{x}, \omega\right) & =\frac{S_{z z}\left(z, k_{x}, \omega\right)}{P_{I}(\omega)} \\
& =A_{2}\left(k_{x}, \omega\right)\left(-\alpha_{2}^{2} \lambda_{2}-2 \alpha_{2}^{2} \mu_{2}-\lambda_{2} k_{x}^{2}\right) \exp \left(\mathrm{i} \alpha_{2} z\right) \\
& +B_{2}\left(k_{x}, \omega\right)\left(-\alpha_{2}^{2} \lambda_{2}-2 \alpha_{2}^{2} \mu_{2}-\lambda_{2} k_{x}^{2}\right) \exp \left(-\mathrm{i} \alpha_{2} z\right) \\
& +C_{2}\left(k_{x}, \omega\right)\left(-2 k_{x} \beta_{2} \mu_{2}\right) \exp \left(\mathrm{i} \beta_{2} z\right)+D_{2}\left(k_{x}, \omega\right)\left(2 k_{x} \beta_{2} \mu_{2}\right) \exp \left(-\mathrm{i} \beta_{2} z\right)
\end{aligned}
$$

The transfer function between the shear stress at location $z$, when $z \leq b$, and the incident pressure can be written as

$$
\begin{aligned}
T\left(z, k_{x}, \omega\right) & =\frac{S_{z x}\left(z, k_{x}, \omega\right)}{P_{I}\left(k_{x}, \omega\right)} \\
& =-A_{1}\left(k_{x}, \omega\right)\left(2 \mu_{1} k_{x} \alpha_{1}\right) \exp \left(\mathrm{i} \alpha_{1} z\right)+B_{1}\left(k_{x}, \omega\right)\left(2 \mu_{1} k_{x} \alpha_{1}\right) \exp \left(-\mathrm{i} \alpha_{1} z\right) \\
& +C_{1}\left(k_{x}, \omega\right)\left[\mu_{1}\left(\beta_{1}^{2}-k_{x}^{2}\right)\right] \exp \left(\mathrm{i} \beta_{1} z\right)+D_{1}\left(k_{x}, \omega\right)\left[\mu_{1}\left(\beta_{1}^{2}-k_{x}^{2}\right)\right] \exp \left(-\mathrm{i} \beta_{1} z\right)
\end{aligned}
$$

or, when $z \geq b$, as

$$
\begin{aligned}
T\left(z, k_{x}, \omega\right) & =\frac{S_{z x}\left(z, k_{x}, \omega\right)}{P_{I}\left(k_{x}, \omega\right)} \\
& =-A_{2}\left(k_{x}, \omega\right)\left(2 \mu_{2} k_{x} \alpha_{2}\right) \exp \left(\mathrm{i} \alpha_{2} z\right)+B_{2}\left(k_{x}, \omega\right)\left(2 \mu_{2} k_{x} \alpha_{2}\right) \exp \left(-\mathrm{i} \alpha_{2} z\right) \\
& +C_{2}\left(k_{x}, \omega\right)\left[\mu_{2}\left(\beta_{2}^{2}-k_{x}^{2}\right)\right] \exp \left(\mathrm{i} \beta_{2} z\right)+D_{2}\left(k_{x}, \omega\right)\left[\mu_{2}\left(\beta_{2}^{2}-k_{x}^{2}\right)\right] \exp \left(-\mathrm{i} \beta_{2} z\right) .
\end{aligned}
$$


Equations (124) through (131) are the open-form solutions to the problem, and these equations provide the correct answer. However, the physics are not evident, and solving a corresponding inverse problem is typically problematic. 


\section{REDUCED-ORDER MODEL}

A reduced-order model presents the transfer functions in a closed form, which is a more desirable expression than the open-form solutions derived in section 2. Deriving a reduced-order model is facilitated by changing the model of the bottom (metallic) plate from an elastic medium to a continuous mass that is infinitely stiff. This is a reasonable assumption because at high frequencies the metallic plate appears rigid to acoustic plane waves, and flexural wave energy does not have a significant dynamic effect on the plate response. Although this assumption limits the model, it is reasonably accurate in the acoustic domain. The boundary conditions of the model at $z=c$ remain equations (33), (34), and (35). The boundary conditions at $z=b$ become

$$
\tau_{z z}(x, b, t)=\left(\lambda_{2}+2 \mu_{2}\right) \frac{\partial u_{z}(x, b, t)}{\partial z}+\lambda_{2} \frac{\partial u_{x}(x, b, t)}{\partial x}=M \frac{\partial^{2} u_{z}(x, b, t)}{\partial t^{2}}
$$

and

$$
\tau_{z x}(x, b, t)=\mu_{2}\left[\frac{\partial u_{x}(x, b, t)}{\partial z}+\frac{\partial u_{z}(x, b, t)}{\partial x}\right]=-M \frac{\partial^{2} u_{x}(x, b, t)}{\partial t^{2}},
$$

where $M$ is the mass per unit area $\left(\mathrm{kg} / \mathrm{m}^{2}\right)$ of the metallic plate. For brevity, the subscript 2 is now dropped from the analysis and unsubscripted material constants are related to the elastomeric plate. Once these boundary conditions are applied to equations (27) and (28), the result is a four-by-four linear system of equations that can be written as

$$
\mathbf{A} \mathbf{x}=\mathbf{b},
$$

where the entries of equation (134) are

$$
\begin{aligned}
& A_{1,1}=-\alpha^{2} \lambda-2 \alpha^{2} \mu-\lambda k_{x}^{2}+\frac{\rho_{f} \omega^{2} \alpha}{\gamma}, \\
& A_{1,2}=-\alpha^{2} \lambda-2 \alpha^{2} \mu-\lambda k_{x}^{2}-\frac{\rho_{f} \omega^{2} \alpha}{\gamma},
\end{aligned}
$$




$$
\begin{aligned}
& A_{1,3}=-2 k_{x} \beta \mu+\frac{\rho_{f} \omega^{2} k_{x}}{\gamma}, \\
& A_{1,4}=2 k_{x} \beta \mu+\frac{\rho_{f} \omega^{2} k_{x}}{\gamma} \text {, } \\
& A_{2,1}=-2 \mu k_{x} \alpha \\
& A_{2,2}=2 \mu k_{x} \alpha \\
& A_{2,3}=\mu \beta^{2}-\mu k_{x}^{2}, \\
& A_{2,4}=\mu \beta^{2}-\mu k_{x}^{2} \\
& A_{3,1}=\left(-\alpha^{2} \lambda-2 \alpha^{2} \mu-\lambda k_{x}^{2}+\mathrm{i} \omega^{2} \alpha M\right) \exp (\mathrm{i} \alpha b), \\
& A_{3,2}=\left(-\alpha^{2} \lambda-2 \alpha^{2} \mu-\lambda k_{x}^{2}-\mathrm{i} \omega^{2} \alpha M\right) \exp (-\mathrm{i} \alpha b), \\
& A_{3,3}=\left(-2 k_{x} \beta \mu+\mathrm{i} \omega^{2} k_{x} M\right) \exp (\mathrm{i} \beta b) \\
& A_{3,4}=\left(2 k_{x} \beta \mu+\mathrm{i} \omega^{2} k_{x} M\right) \exp (-\mathrm{i} \beta b), \\
& A_{4,1}=\left(-2 \mu k_{x} \alpha-\mathrm{i} \omega^{2} k_{x} M\right) \exp (\mathrm{i} \alpha b) \\
& A_{4,2}=\left(2 \mu k_{x} \alpha-\mathrm{i} \omega^{2} k_{x} M\right) \exp (-\mathrm{i} \alpha b) \\
& A_{4,3}=\left(\mu \beta^{2}-\mu k_{x}^{2}+\mathrm{i} \omega^{2} \beta M\right) \exp (\mathrm{i} \beta b), \\
& A_{4,4}=\left(\mu \beta^{2}-\mu k_{x}^{2}-\mathrm{i} \omega^{2} \beta M\right) \exp (-\mathrm{i} \beta b), \\
& x_{1,1}=A\left(k_{x}, \omega\right) \text {, } \\
& x_{2,1}=B\left(k_{x}, \omega\right) \text {, }
\end{aligned}
$$




$$
\begin{aligned}
& x_{3,1}=C\left(k_{x}, \omega\right), \\
& x_{4,1}=D\left(k_{x}, \omega\right), \\
& b_{1,1}=-2 P_{I}(\omega), \\
& b_{2,1}=0 \\
& b_{3,1}=0,
\end{aligned}
$$

and

$$
b_{4,1}=0
$$

Using equations (135) through (158), the solution to the constants $A, B, C$, and $D$ can be found by

$$
\mathbf{x}=\mathbf{A}^{-1} \mathbf{b}
$$

The right-hand side of equation (159) can be solved in a closed-form solution by inverting the A matrix and multiplying the results by the $\mathbf{b}$ vector. The constants in the $\mathbf{x}$ vector are known explicitly and can be re-inserted into equations (125), (127), (129), and (131) to solve for the displacements and stresses. In addition, the determinant of the system matrix is available as

$$
\operatorname{det}(\mathbf{A})=4 \mu^{3} \Delta\left(k_{x}, \omega\right)
$$

where

$$
\begin{aligned}
\Delta\left(k_{x}, \omega\right) & =d_{1}+d_{2} \cos (\alpha h) \cos (\beta h)+d_{3} \cos (\alpha h) \sin (\beta h) \\
& +d_{4} \sin (\alpha h) \cos (\beta h)+d_{5} \sin (\alpha h) \sin (\beta h),
\end{aligned}
$$

with

$$
d_{1}=4 \alpha \beta k_{x}^{2}\left(\beta^{2}-k_{x}^{2}\right)\left[2\left(\beta^{2}-k_{x}^{2}\right)-(M / \rho)^{2}\left(\beta^{2}+k_{x}^{2}\right)^{2}\right]
$$




$$
\begin{aligned}
d_{2} & =-\alpha \beta\left[8 k_{x}^{2}\left(\beta^{2}-k_{x}^{2}\right)^{2}+(M / \rho)^{2}\left(\beta^{2}+k_{x}^{2}\right)^{2}\left(5 k_{x}^{4}-2 k_{x}^{2} \beta^{2}+\beta^{4}\right)\right. \\
& \left.+\mathrm{i}\left(\rho_{f} / \rho \gamma\right)(M / \rho)\left(\beta^{2}+k_{x}^{2}\right)^{4}\right], \\
d_{3}= & \mathrm{i} \alpha\left(\beta^{2}+k_{x}^{2}\right)^{2}\left[\left(\rho_{f} / \rho \gamma\right)\left(\beta^{4}-2 \beta^{2} k_{x}^{2}+k_{x}^{4}\right)\right. \\
& \left.+-\mathrm{i}(M / \rho)\left(\beta^{4}-6 \beta^{2} k_{x}^{2}+k_{x}^{4}\right)+\left(\rho_{f} / \rho \gamma\right)(M / \rho)^{2} k_{x}^{2}\left(\beta^{2}+k_{x}^{2}\right)^{2}\right], \\
d_{4}= & \mathrm{i} \beta\left(\beta^{2}+k_{x}^{2}\right)^{2}\left[4\left(\rho_{f} / \rho \gamma\right) \alpha^{2} k_{x}^{2}\right. \\
& +\mathrm{i}(M / \rho)\left(\beta^{2}+2 \alpha k_{x}-k_{x}^{2}\right)\left(\beta^{2}-2 \alpha k_{x}-k_{x}^{2}\right) \\
& \left.+\left(\rho_{f} / \rho \gamma\right)(M / \rho)^{2} \alpha^{2}\left(\beta^{2}+k_{x}^{2}\right)^{2}\right],
\end{aligned}
$$

and

$$
\begin{aligned}
d_{5}= & \left(\beta^{2}-k_{x}^{2}\right)^{4}+16 k_{x}^{4} \alpha^{2} \beta^{2}+ \\
& (M / \rho)^{2} k_{x}^{2}\left(\beta^{2}+k_{x}^{2}\right)^{2}\left[4 \alpha^{2} \beta^{2}+\left(\beta^{2}-k_{x}^{2}\right)^{2}\right] \\
& +-\mathrm{i}\left(\rho_{f} / \rho \gamma\right)(M / \rho) \alpha^{2}\left(\beta^{2}+k_{x}^{2}\right)^{4} .
\end{aligned}
$$

Once the determinant of the system is known, the transfer function between the tangential displacement and the incident pressure can be computed by

$$
T\left(z, k_{x}, \omega\right)=\frac{U_{x}\left(z, k_{x}, \omega\right)}{P_{I}(\omega)}=\frac{U_{x}^{T}\left(z, k_{x}, \omega\right)}{\mu \Delta\left(k_{x}, \omega\right)},
$$

where

$$
\begin{aligned}
U_{x}^{T}\left(z, k_{x}, \omega\right)= & \mathrm{i} k_{x} c_{1} \cos (\alpha z)+\mathrm{i} k_{x} c_{2} \sin [\alpha(h+z)] \sin (\beta h) \\
& +\mathrm{i} k_{x} c_{3} \cos [\alpha(h+z)] \sin (\beta h)+\mathrm{i} k_{x} c_{4} \sin [\alpha(h+z)] \cos (\beta h) \\
& +\mathrm{i} k_{x} c_{5} \cos [\alpha(h+z)] \cos (\beta h)+\mathrm{i} \beta c_{6} \cos (\beta z) \\
& +\mathrm{i} \beta c_{7} \sin [\beta(h+z)] \sin (\alpha h)+\mathrm{i} \beta c_{8} \cos [\beta(h+z)] \sin (\alpha h) \\
& +\mathrm{i} \beta c_{9} \sin [\beta(h+z)] \cos (\alpha h)+\mathrm{i} \beta c_{10} \cos [\beta(h+z)] \cos (\alpha h),
\end{aligned}
$$


with

$$
\begin{aligned}
& c_{1}=4 \alpha \beta k_{x}^{2}\left[2\left(\beta^{2}-k_{x}^{2}\right)-(M / \rho)^{2}\left(\beta^{2}+k_{x}^{2}\right)^{2}\right], \\
& c_{2}=2\left(\beta^{2}-k_{x}^{2}\right)\left[\left(\beta^{2}-k_{x}^{2}\right)^{2}+(M / \rho)^{2} k_{x}^{2}\left(\beta^{2}+k_{x}^{2}\right)^{2}\right], \\
& c_{3}=2 \alpha(M / \rho)\left(\beta^{2}-k_{x}^{2}\right)\left(\beta^{2}+k_{x}^{2}\right)^{2}, \\
& c_{4}=-2 \beta(M / \rho)\left(\beta^{2}-k_{x}^{2}\right)\left(\beta^{2}+k_{x}^{2}\right)^{2}, \\
& c_{5}=-2 \alpha \beta\left(\beta^{2}-k_{x}^{2}\right)\left[4 k_{x}^{2}+(M / \rho)^{2}\left(\beta^{2}+k_{x}^{2}\right)^{2}\right], \\
& c_{6}=-2 \alpha k_{x}\left(\beta^{2}-k_{x}^{2}\right)\left[2\left(\beta^{2}-k_{x}^{2}\right)-(M / \rho)^{2}\left(\beta^{2}+k_{x}^{2}\right)^{2}\right], \\
& c_{7}=-4 \alpha^{2} \beta k_{x}\left[4 k_{x}^{2}+(M / \rho)^{2}\left(\beta^{2}+k_{x}^{2}\right)^{2}\right], \\
& c_{8}=-4 \alpha^{2} k_{x}(M / \rho)\left(\beta^{2}+k_{x}^{2}\right)^{2}, \\
& c_{9}=4 \alpha \beta k_{x}(M / \rho)\left(\beta^{2}+k_{x}^{2}\right)^{2},
\end{aligned}
$$

and

$$
c_{10}=4 \alpha k_{x}\left[\left(\beta^{2}-k_{x}^{2}\right)^{2}+(M / \rho)^{2} k_{x}^{2}\left(\beta^{2}+k_{x}^{2}\right)^{2}\right]
$$

The transfer function between the normal displacement and the incident pressure can be computed by

$$
T\left(z, k_{x}, \omega\right)=\frac{U_{z}\left(z, k_{x}, \omega\right)}{P_{I}(\omega)}=\frac{U_{z}^{T}\left(z, k_{x}, \omega\right)}{\mu \Delta\left(k_{x}, \omega\right)},
$$

where 


$$
\begin{aligned}
U_{z}^{T}\left(z, k_{x}, \omega\right) & =-\alpha c_{1} \sin (\alpha z)+\alpha c_{2} \cos [\alpha(h+z)] \sin (\beta h) \\
& +-\alpha c_{3} \sin [\alpha(h+z)] \sin (\beta h)+\alpha c_{4} \cos [\alpha(h+z)] \cos (\beta h) \\
& +-\alpha c_{5} \sin [\alpha(h+z)] \cos (\beta h)+k_{x} c_{6} \sin (\beta z) \\
& +-k_{x} c_{7} \cos [\beta(h+z)] \sin (\alpha h)+k_{x} c_{8} \sin [\beta(h+z)] \sin (\alpha h) \\
& +-k_{x} c_{9} \cos [\beta(h+z)] \cos (\alpha h)+k_{x} c_{10} \sin [\beta(h+z)] \cos (\alpha h)
\end{aligned}
$$

The transfer function between the shear stress and the incident pressure can be calculated using

$$
T\left(z, k_{x}, \omega\right)=\frac{S_{z x}\left(z, k_{x}, \omega\right)}{P_{I}(\omega)}=\frac{S_{z x}^{T}\left(z, k_{x}, \omega\right)}{\Delta\left(k_{x}, \omega\right)}
$$

where

$$
\begin{aligned}
S_{z x}^{T}\left(z, k_{x}, \omega\right) & =-2 \mathrm{i} \alpha k_{x} c_{1} \sin (\alpha z)+2 \mathrm{i} \alpha k_{x} c_{2} \cos [\alpha(h+z)] \sin (\beta h) \\
& +-2 \mathrm{i} \alpha k_{x} c_{3} \sin [\alpha(h+z)] \sin (\beta h)+2 \mathrm{i} \alpha k_{x} c_{4} \cos [\alpha(h+z)] \cos (\beta h) \\
& +-2 \mathrm{i} \alpha k_{x} c_{5} \sin [\alpha(h+z)] \cos (\beta h)-\mathrm{i}\left(\beta^{2}-k_{x}^{2}\right) c_{6} \sin (\beta z) \\
& +\mathrm{i}\left(\beta^{2}-k_{x}^{2}\right) c_{7} \cos [\beta(h+z)] \sin (\alpha h)-\mathrm{i}\left(\beta^{2}-k_{x}^{2}\right) c_{8} \sin [\beta(h+z)] \sin (\alpha h) \\
& +\mathrm{i}\left(\beta^{2}-k_{x}^{2}\right) c_{9} \cos [\beta(h+z)] \cos (\alpha h)-\mathrm{i}\left(\beta^{2}-k_{x}^{2}\right) c_{10} \sin [\beta(h+z)] \cos (\alpha h) .
\end{aligned}
$$

The transfer function between the normal stress and the incident pressure can be calculated using

$$
T\left(z, k_{x}, \omega\right)=\frac{S_{z z}\left(z, k_{x}, \omega\right)}{P_{I}(\omega)}=\frac{S_{z z}^{T}\left(z, k_{x}, \omega\right)}{\Delta\left(k_{x}, \omega\right)}
$$

where

$$
\begin{aligned}
S_{z=}^{T}\left(z, k_{x}, \omega\right) & =-\left(\beta^{2}-k_{x}^{2}\right) c_{1} \cos (\alpha z)-\left(\beta^{2}-k_{x}^{2}\right) c_{2} \sin [\alpha(h+z)] \sin (\beta h) \\
& +-\left(\beta^{2}-k_{x}^{2}\right) c_{3} \cos [\alpha(h+z)] \sin (\beta h)+-\left(\beta^{2}-k_{x}^{2}\right) c_{4} \sin [\alpha(h+z)] \cos (\beta h) \\
& +-\left(\beta^{2}-k_{x}^{2}\right) c_{5} \cos [\alpha(h+z)] \cos (\beta h)+2 \beta k_{x} c_{6} \cos (\beta z) \\
& +2 \beta k_{x} c_{7} \sin [\beta(h+z)] \sin (\alpha h)+2 \beta k_{x} c_{8} \cos [\beta(h+z)] \sin (\alpha h) \\
& +2 \beta k_{x} c_{9} \sin [\beta(h+z)] \cos (\alpha h)+2 \beta k_{x} c_{10} \cos [\beta(h+z)] \cos (\alpha h) .
\end{aligned}
$$


The reflected pressure field in the fluid is equal to

$$
P_{R}\left(z_{f}, k_{x}, \omega\right)=\left[\left(\frac{\omega^{2} \rho_{f}}{\mathrm{i} \gamma}\right) U_{z}\left(b, k_{x}, \omega\right)+1\right] \exp \left(\mathrm{i} \gamma z_{f}\right),
$$

with $z_{f}$ being the position where the field is evaluated $(\mathrm{m})$. The total pressure field is the sum of the reflected pressure field and the spatially phase-shifted excitation level. It is written as

$$
P_{\text {Total }}\left(z_{f}, k_{x}, \omega\right)=P_{R}\left(z_{f}, k_{x}, \omega\right)+P_{l}(\omega) \exp \left(-\mathrm{i} \gamma z_{f}\right)
$$

Equations (132) to (186) are the reduced-order model. 


\section{COMPARISON OF MODELS}

By comparing the full- and the reduced-order models, the effects of modeling the metallic backing piece as a discrete mass rather than as a thick plate can be discerned. The baseline model includes an elastomer with the properties of $\rho=1200 \mathrm{~kg} / \mathrm{m}^{3}, \lambda=9.8 \mathrm{e} 8(1-0.0163 i) \mathrm{N} / \mathrm{m}^{2}$, $\mu=1 \mathrm{e} 7(1-0.2 \mathrm{i}) \mathrm{N} / \mathrm{m}^{2}$, and $h=0.0508 \mathrm{~m}$; a steel backing plate with the properties of $\rho=7850 \mathrm{~kg} / \mathrm{m}^{3}, \lambda=1.21 \mathrm{el} 1(1-0.01 \mathrm{i}) \mathrm{N} / \mathrm{m}^{2}, \mu=8.04 \mathrm{el} 0(1-0.01 i) \mathrm{N} / \mathrm{m}^{2}$, and $h=0.0127 \mathrm{~m} ;$ and fluid with the properties of $\rho=1025 \mathrm{~kg} / \mathrm{m}^{3}$ and $c_{f}=1500 \mathrm{~m} / \mathrm{s}$. The model is evaluated at $z=-0.0381 \mathrm{~m}$. Figures 2 through 11 present the system responses versus incident angles at frequencies from $10 \mathrm{kHz}$ to $100 \mathrm{kHz}$ in $10-\mathrm{kHz}$ increments. In each of the figures, the solid line is the double-plate model developed in section 2 and the " $x$ " marks are the reduced-order model developed in section 3. In addition, the two plots in the upper left of each of the figures are the magnitude and phase angle of the normal displacement divided by incident angle pressure versus incident angle. The two plots in the upper right are the magnitude and phase angle of the tangential displacement divided by incident angle pressure versus incident angle. The two plots in the lower left are the magnitude and phase angle of the normal stress divided by incident angle pressure versus incident angle. The two plots in the lower right are the magnitude and phase angle of the shear stress divided by incident angle pressure versus incident angle. It is evident that at most frequencies the reduced-order model is equivalent to the double-plate model. The two models diverge somewhat at some specific incident angles. This disagreement corresponds to elastic waves in the full-order model that are not present in the reduced-order model. If the mass of the metallic plate is increased, the comparison will be more favorable. If the mass of the metallic plate is decreased, the two models will begin to deviate from one another. 

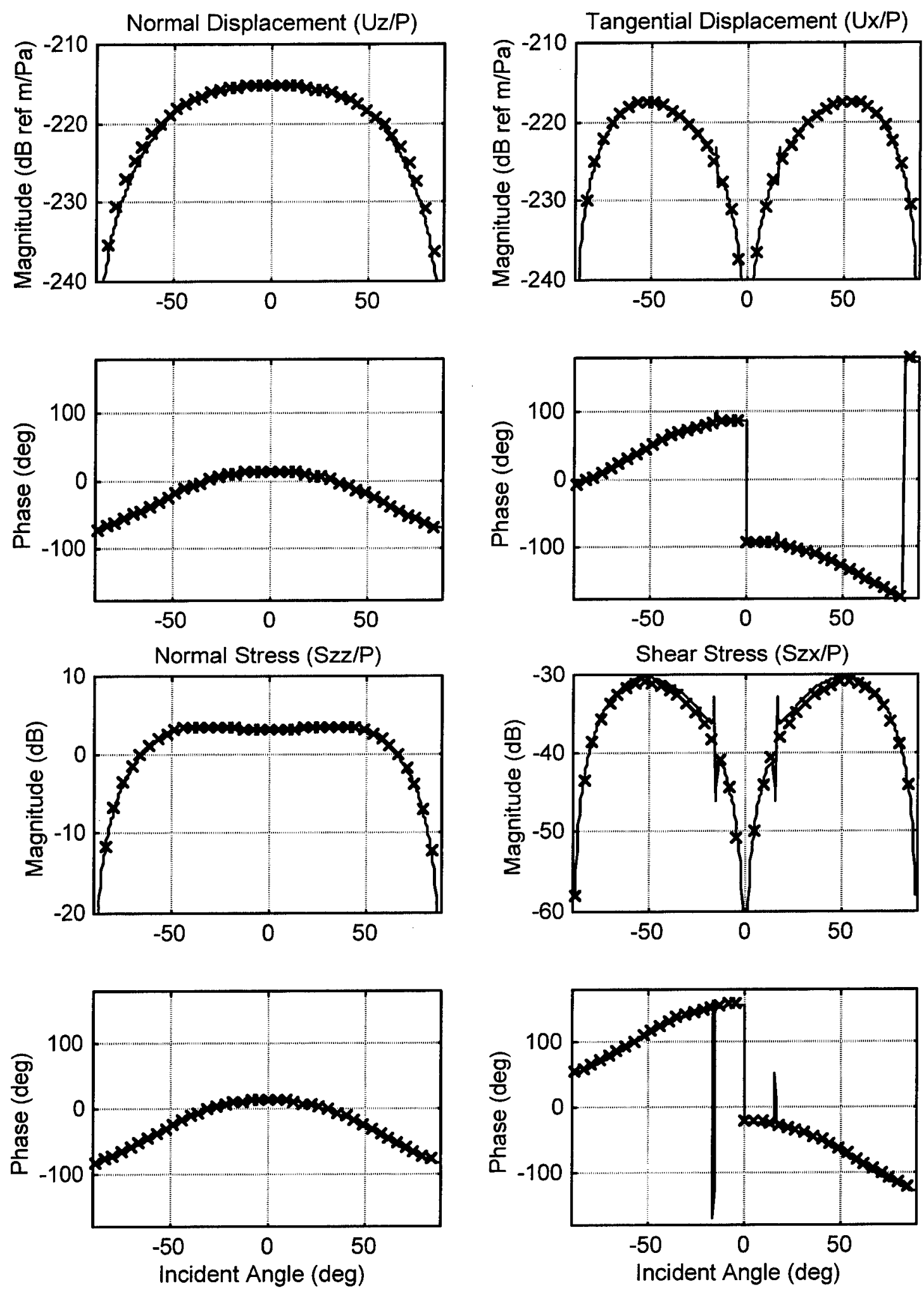

Figure 2. System Response Versus Incident Angle for $f=10,000 \mathrm{~Hz}$ 

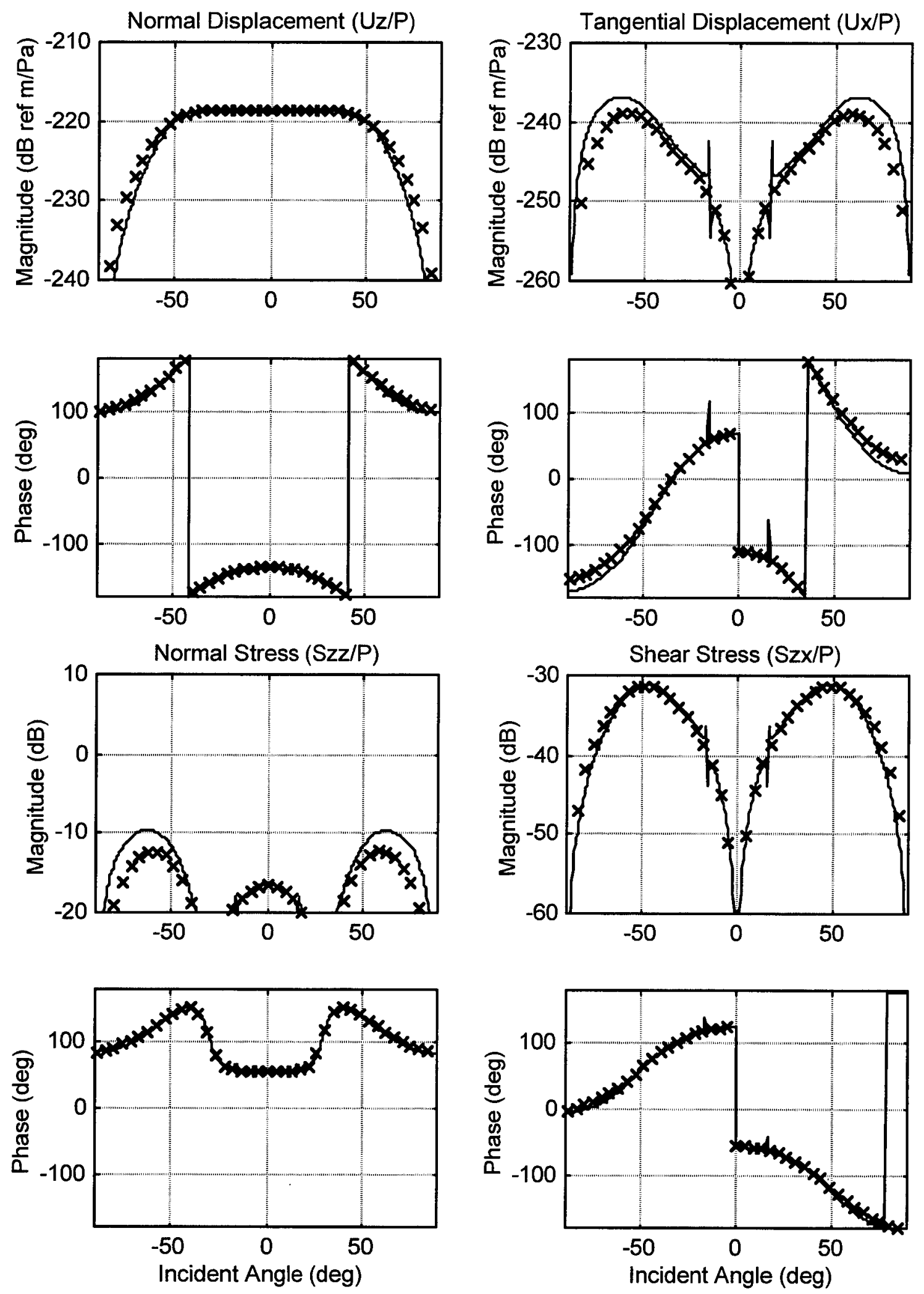

Figure 3. System Response Versus Incident Angle for $f=20,000 \mathrm{~Hz}$ 

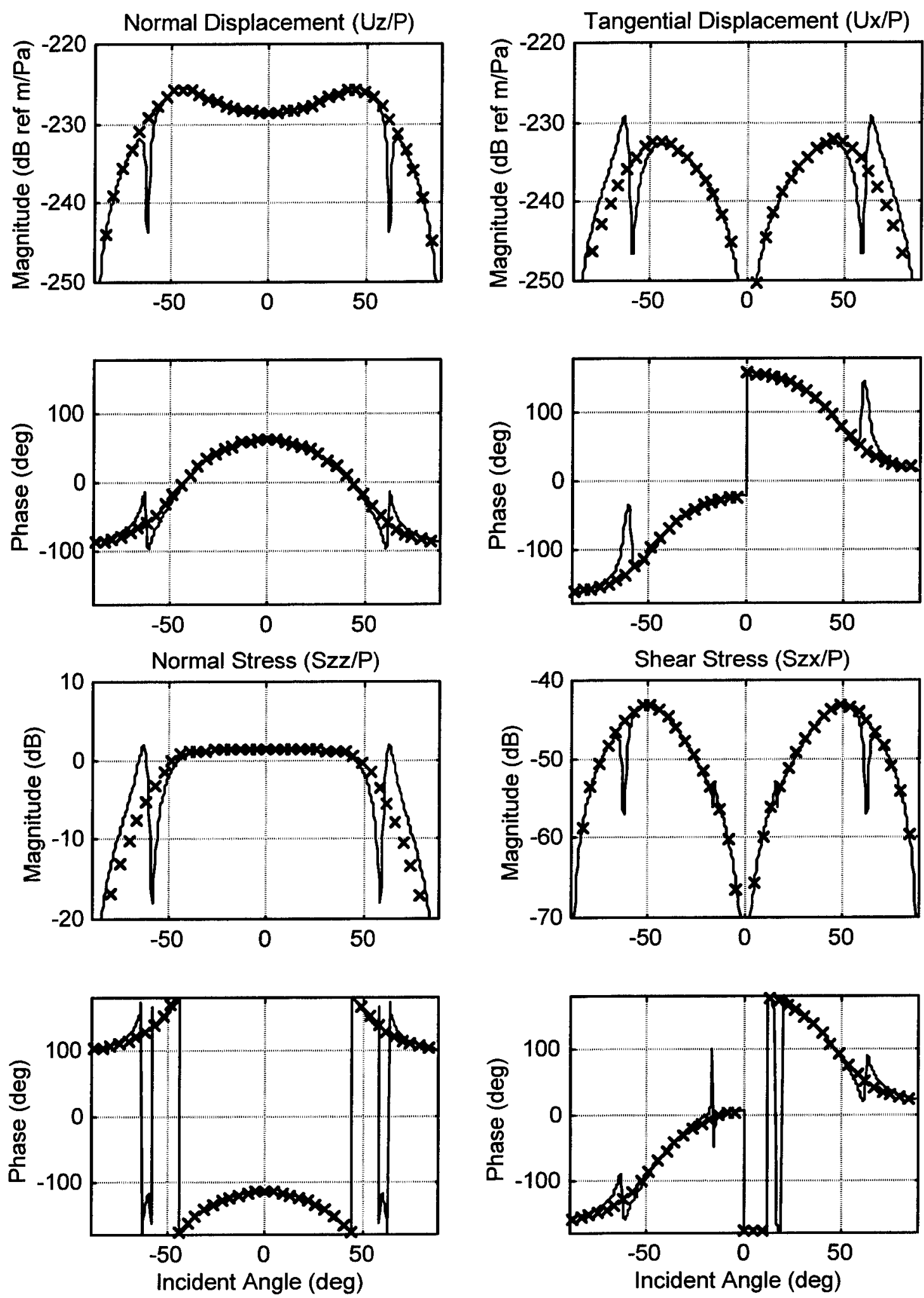

Figure 4. System Response Versus Incident Angle for $f=30,000 \mathrm{~Hz}$ 

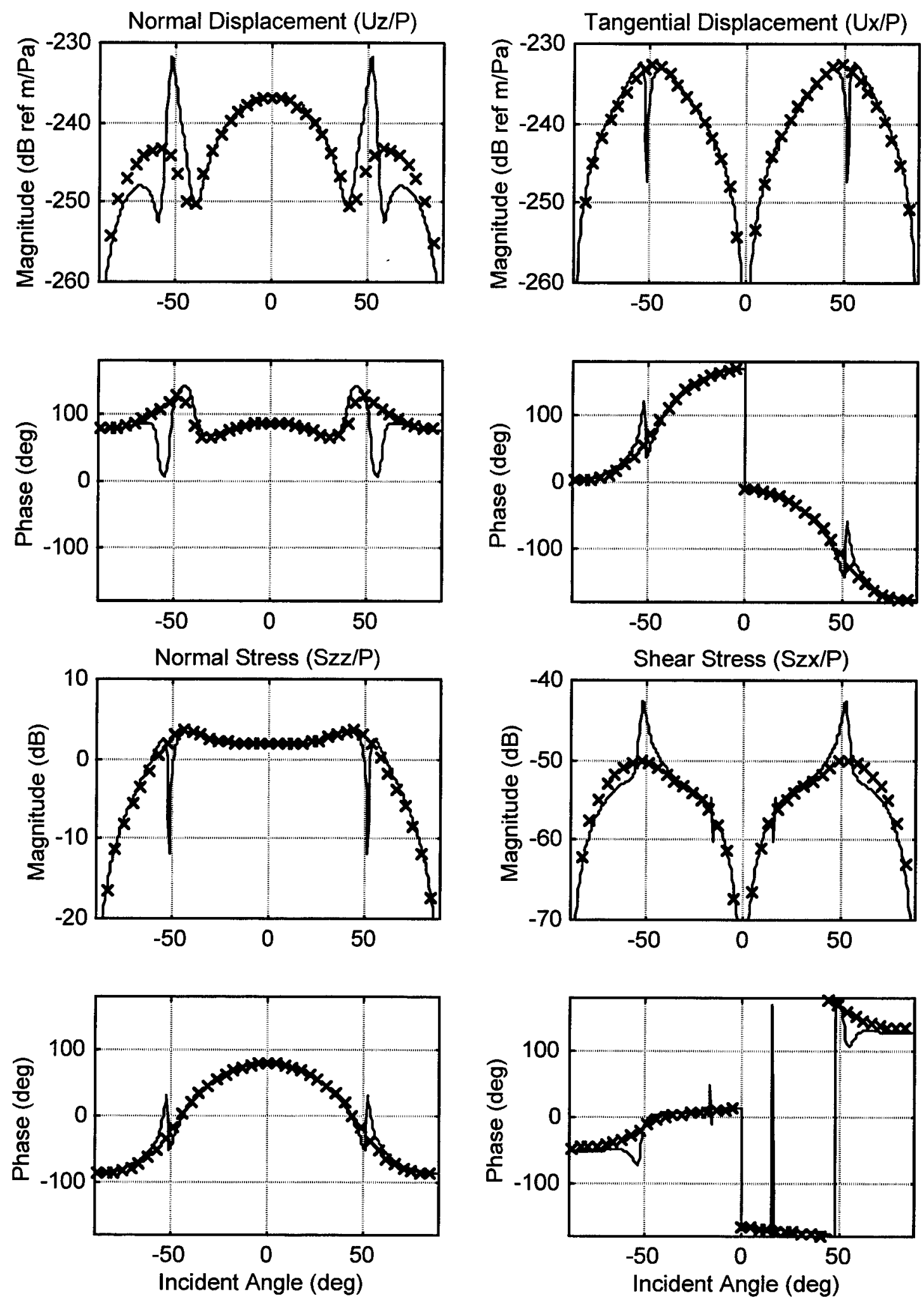

Figure 5. System Response Versus Incident Angle for $f=40,000 \mathrm{~Hz}$ 

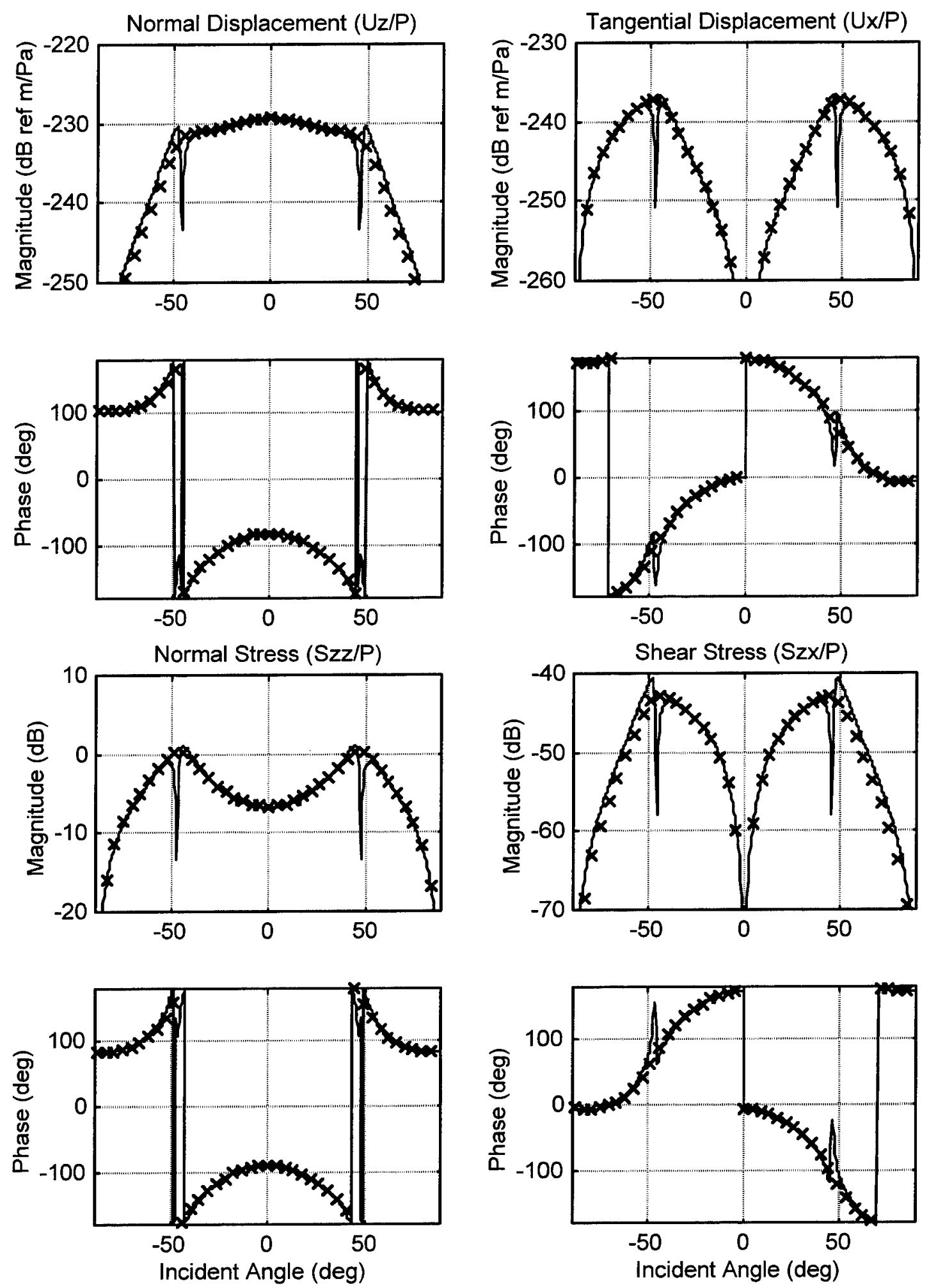

Figure 6. System Response Versus Incident Angle for $f=50,000 \mathrm{~Hz}$ 

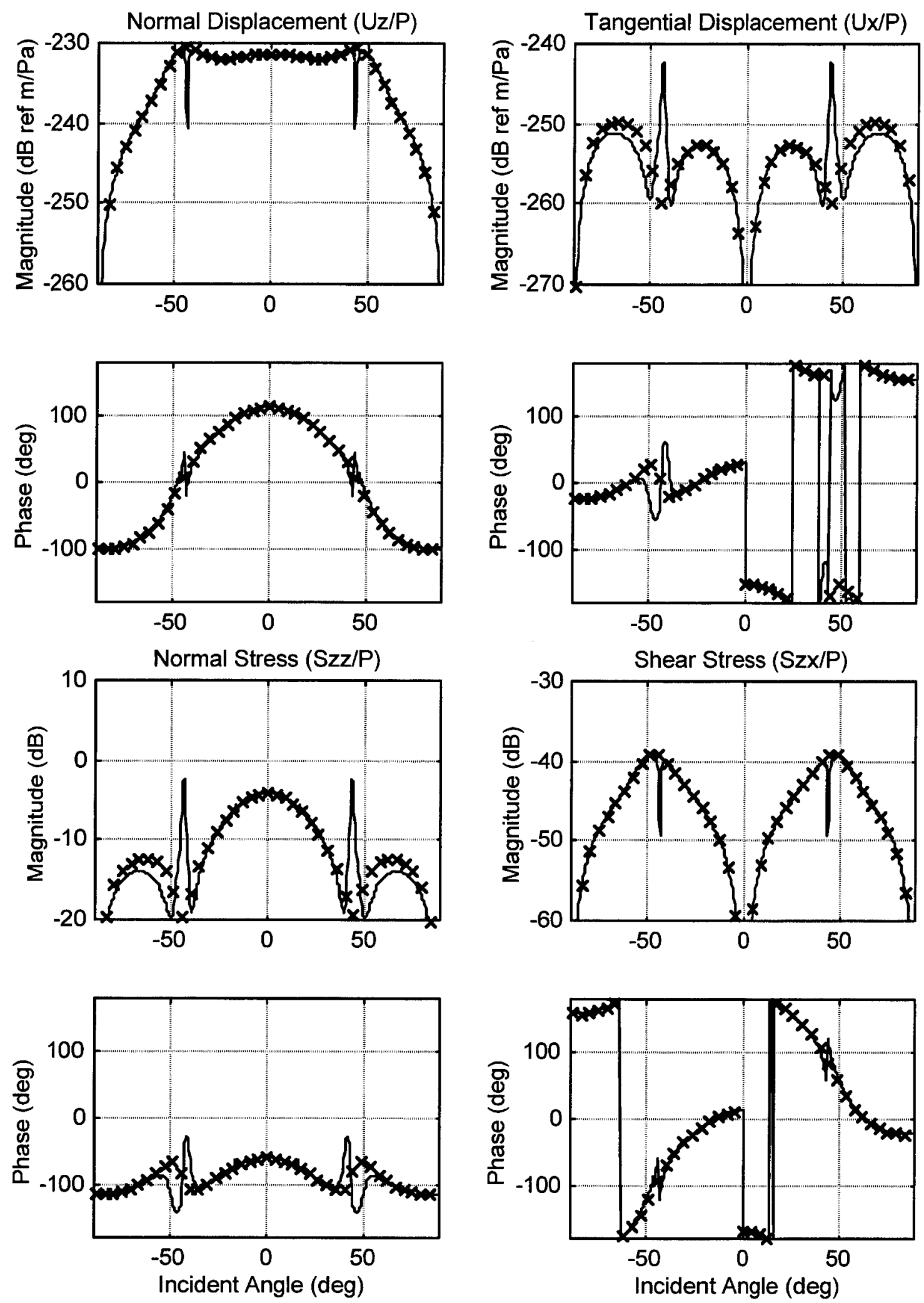

Figure 7. System Response Versus Incident Angle for $f=60,000 \mathrm{~Hz}$ 

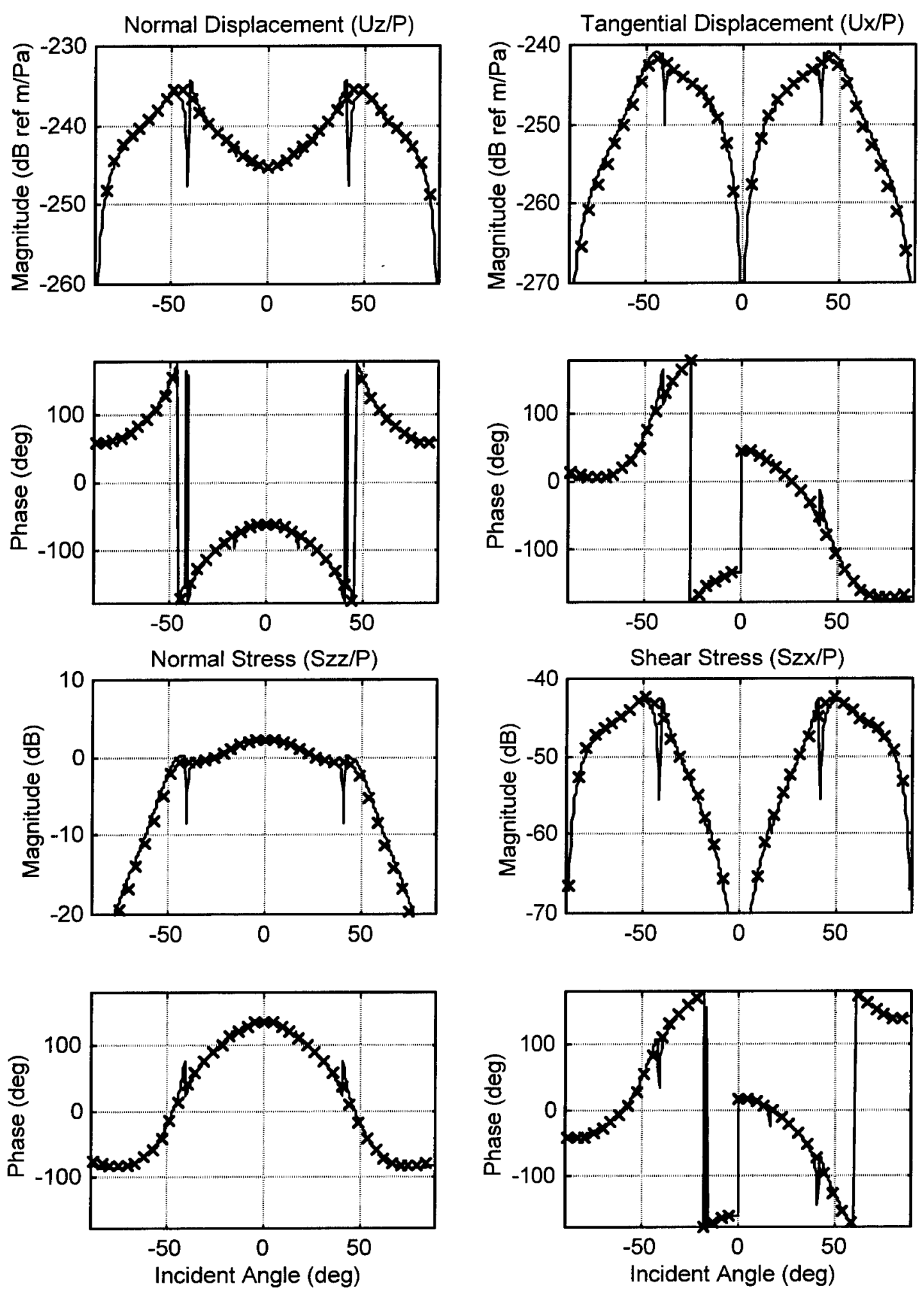

Figure 8. System Response Versus Incident Angle for $\mathrm{f}=70,000 \mathrm{~Hz}$ 

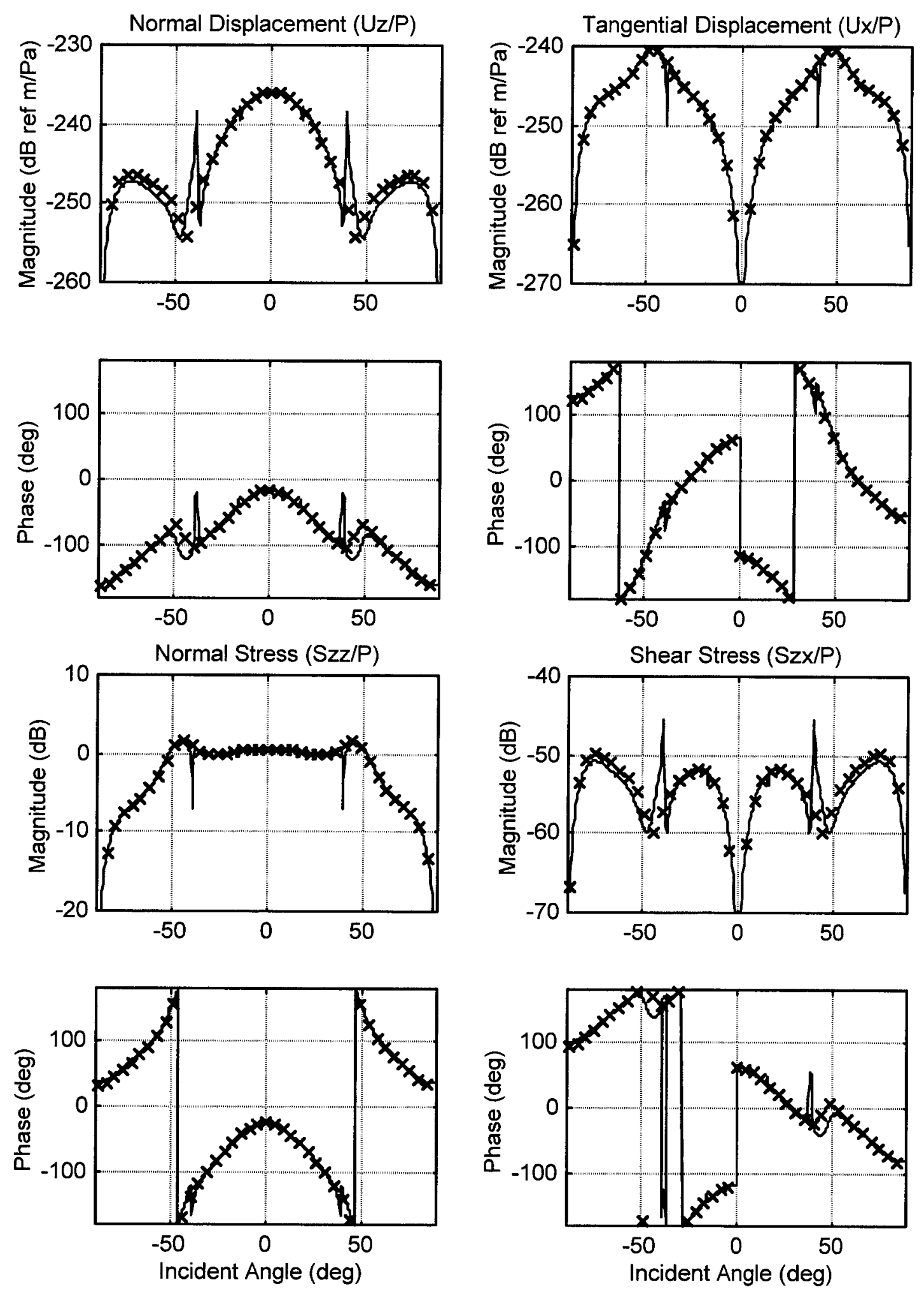

Figure 9. System Response Versus Incident Angle for $f=80,000 \mathrm{~Hz}$ 

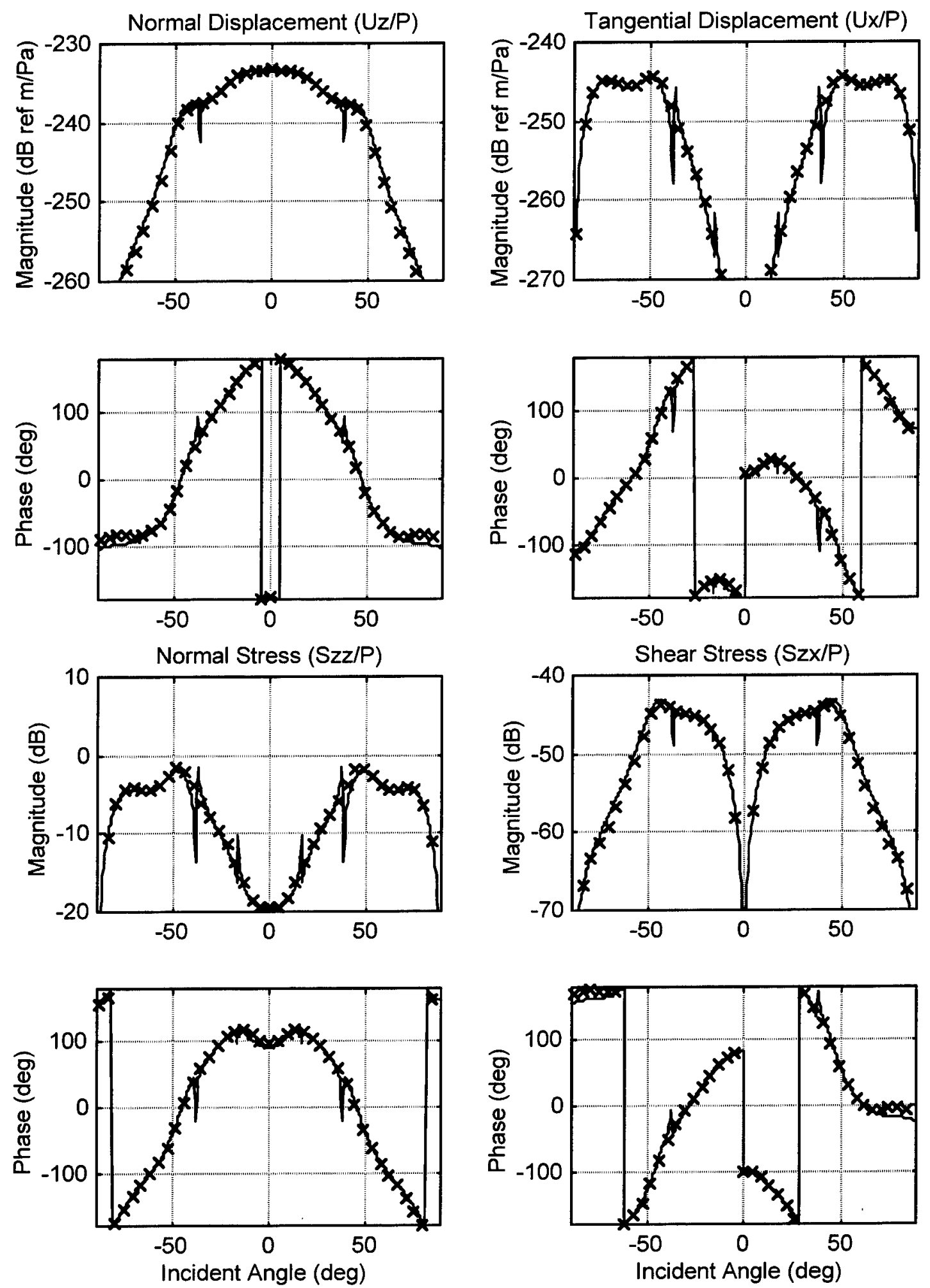

Figure 10. System Response Versus Incident Angle for $f=90,000 \mathrm{~Hz}$ 

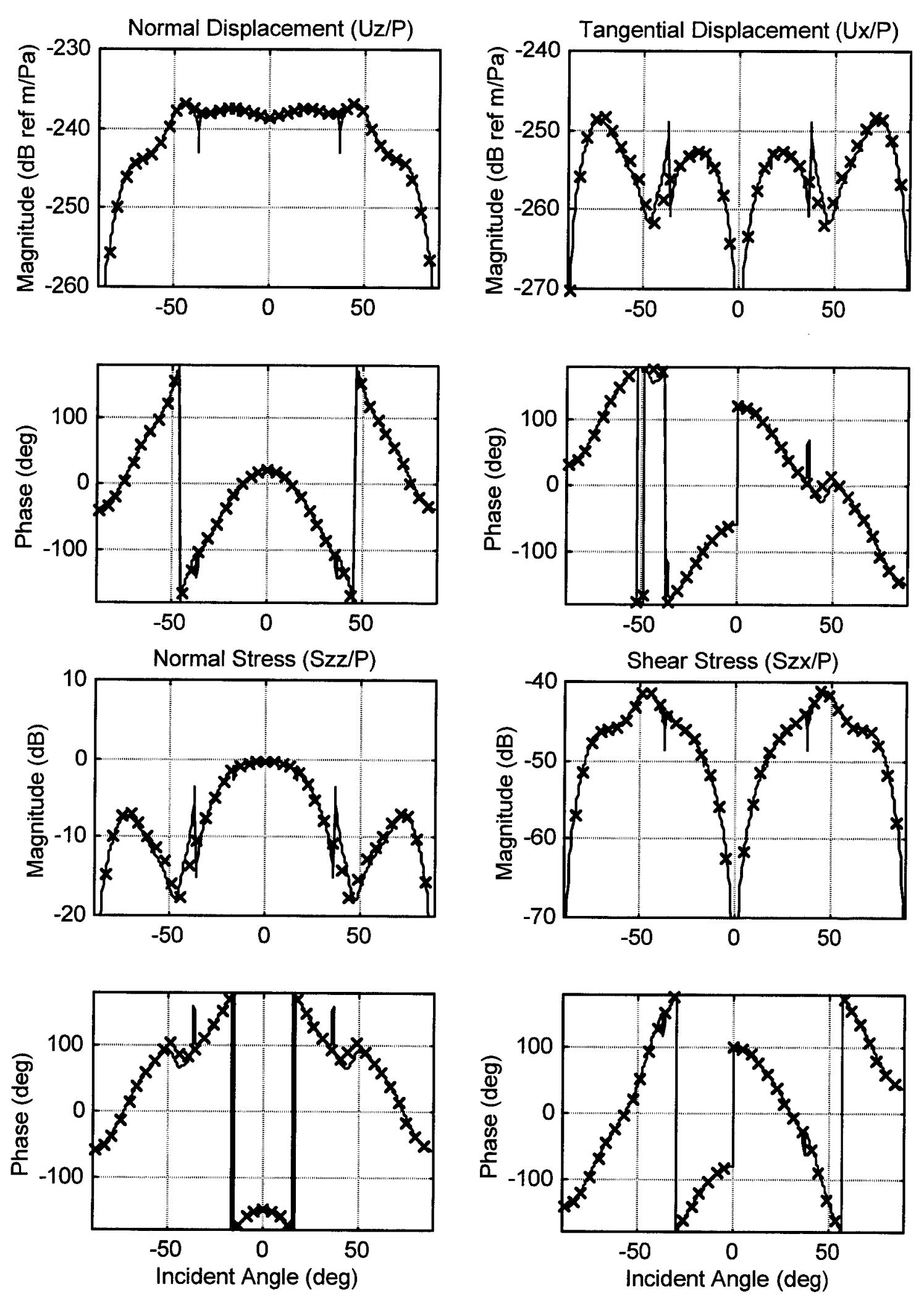

Figure 11. System Response Versus Incident Angle for $f=100,000 \mathrm{~Hz}$ 


\section{CONCLUSIONS}

This report has developed a reduced-order model that provides a closed-form solution to the problem of a fluid-loaded, elastomeric-coated metallic plate. This solution form is useful because the dynamics of the problem are now explicit and the contribution of each term to the solution is clearly evident. This solution has been compared to the open-form (implicit) solution of a fluid-loaded, double-thick plate system from $10 \mathrm{kHz}$ to $100 \mathrm{kHz}$. The result is that the reduced-order model is almost identical to the open-form solution for all the field variables. This solution is limited to the case where a stiff plate is covered by a relatively soft plate. Further work in this area should be undertaken with experiments so that actual data can be compared to the models.

\section{REFERENCES}

1. S. P. Timoshenko and J. N. Goodier, Theory of Elasticity, McGraw-Hill, New York, 1934.

2. M. C. Potter, Mathematical Methods in the Physical Sciences, Prentice-Hall, Englewood Cliffs, NJ, 1978.

3. K. F. Graff, Wave Motion in Elastic Solids, Dover Publications, New York, NY, 1975.

4. L. J. Ziomek, Fundamentals of Acoustic Field Theory and Space-Time Signal Processing, CRC Press, Boca Raton, FL, 1995.

5. A. J. Hull, "Analysis of a Fluid-Loaded Thick Plate," NUWC-NPT Technical Report 11,389, Naval Undersea Warfare Center Division, Newport, RI, 1 October 2002. 


\section{INITIAL DISTRIBUTION LIST}

Addressee

Office of Naval Research (ONR 333 (D. Drumheller))

Center for Naval Analyses

Defense Technical Information Center
No. of Copies

2

1

2 